\title{
Characteristics of recovered COVID-19 patients with recurrent positive RT-PCR findings in Wuhan, China: a retrospective study
}

Tie-Jun Shui ${ }^{1 \dagger}$, Chao Li ${ }^{2 \dagger}$, Hong-bing Liu ${ }^{3}$, Xiaohua Chen ${ }^{4,5^{*}}$ (D) and Bi-ke Zhang ${ }^{6 *}$

\begin{abstract}
Background: Two months after the outbreak of coronavirus disease 2019 (COVID-19) in Wuhan, China, tens of thousands of hospitalized patients had recovered, and little is known about the follow-up of the recovered patients.

Methods: The clinical characteristics, reverse transcriptase-polymerase chain reaction (RT-PCR) results from throat swab specimens and the results of serological COVID-19 rapid diagnostic test (RDT) for severe acute respiratory syndrome coronavirus 2 (SARS-CoV-2) were retrospectively reviewed for a total of 758 recovered patients who were previously hospitalized in 17 hospitals and quarantined at 32 rehabilitation stations in Wuhan, China.

Results: In total, 59 patients (7.78\%) had recurrent positive findings for COVID-19 on RT-PCR from throat swabs. With regard to antibody detection, 50/59 (84.75\%) and 4/59 (6.78\%) patients had positive lgG or dual positive lgG/ IgM RDT results, respectively.

Conclusions: Some patients who had been quarantined and had subsequently recovered from COVID-19 had recurrent positive RT-PCR results for SARS-CoV-2, and the possibility of transmission of the virus by recovered patients needs further investigation.
\end{abstract}

Trial registration: Current Controlled Trials ChiCTR2000033580, Jun 6th 2020. Retrospectively registered.

Keywords: SARS-CoV-2, COVID-19, Recurrent, RT-PCR

\section{Background}

Coronavirus disease 2019 (COVID-19) is an emerging infectious respiratory disease caused by severe acute respiratory syndrome coronavirus 2 (SARS-CoV-2) that first emerged in early December 2019 in Wuhan, China. As of March 15, COVID-19 had affected 81,062 individuals in

\footnotetext{
* Correspondence: hannahchen2003@163.com; zbk0128@sina.com

${ }^{\dagger}$ Tie-Jun Shui and Chao Li contributed equally to this work.

${ }^{4}$ Beijing Tropical Medicine Research Institute, Beijing Friendship Hospital, Capital Medical University, Beijing 100050, China

${ }^{6}$ Chinese Center for Disease Control and Prevention, Beijing 102206, China Full list of author information is available at the end of the article
}

China, and 67,041 had recovered after the application of multiple aggressive treatments.

According to the national recommendations for the diagnosis and treatment of pneumonia caused by SARSCoV-2 (5th edition) and the current status of clinical practice in Hubei Province, real-time reverse transcriptase-polymerase chain reaction (RT-PCR) was used to detect SARS-CoV-2 in respiratory secretions $[1,2]$. The patients suspected of having COVID-19 were diagnosed by positive RT-PCR for SARS-CoV-2, and 2 consecutively negative RT-PCR results were used as a criterion for hospital discharge. Then, the patients who had recovered from COVID-19 were quarantined at the

C C The Author(s). 2020 Open Access This article is licensed under a Creative Commons Attribution 4.0 International License, which permits use, sharing, adaptation, distribution and reproduction in any medium or format, as long as you give appropriate credit to the original author(s) and the source, provide a link to the Creative Commons licence, and indicate if changes were made. The images or other third party material in this article are included in the article's Creative Commons licence, unless indicated otherwise in a credit line to the material. If material is not included in the article's Creative Commons licence and your intended use is not permitted by statutory regulation or exceeds the permitted use, you will need to obtain permission directly from the copyright holder. To view a copy of this licence, visit http://creativecommons.org/licenses/by/4.0/ The Creative Commons Public Domain Dedication waiver (http://creativecommons.org/publicdomain/zero/1.0/) applies to the data made available in this article, unless otherwise stated in a credit line to the data. 
rehabilitation stations, and RT-PCR was performed to determine whether they could return to work.

Few studies have described positive RT-PCR test results in patients who have recovered from COVID-19 [3-5], and the clinical characteristics of the recovered COVID-19 patients with recurrent positive RT-PCR results remain unclear. Here, we studied the characteristics of recovered COVID-19 patients with recurrent positive RT-PCR results for SARS-CoV-2 in Huangpi, Wuhan.

\section{Methods}

\section{Data sources}

We conducted a retrospective study focusing on consecutive patients with a confirmed diagnosis of COVID19 who were hospitalized and quarantined at the rehabilitation stations from February 25, 2020, to March 15, 2020, from Huangpi district in Wuhan, China. The diagnosis of patients was based on the 5th edition of the National Guidelines for the Prevention and Control of the Novel Coronavirus Pneumonia (PC-NCP) published by the National Health Commission of China on February 8, 2020 [1]. The patients with a laboratory-confirmed infection who had 2 consecutive negative RT-PCR results before hospital discharge separated by at least 1 day were enrolled. A total of 758 patients with a confirmed diagnosis of COVID-19 were hospitalized in 17 hospitals and then quarantined at 32 rehabilitation stations in Huangpi district in Wuhan, China. The basic patient information, clinical severity of COVID-19, and results of RT-PCR for SARS-CoV-2 in throat swabs were noted and analysed. This study was approved by the ethics committee of the Yunnan Center for Disease Control and Prevention, Yunnan, China, and all patients gave written informed consent.

\section{RT-PCR detection of SARS-CoV-2}

Real-time RT-PCR was performed on throat swab specimens at Wuhan Ping an Hao Medical Laboratory according to the protocol from DAAN Gene Co., Ltd., of Sun Yat-sen University. SARS-CoV-2 open reading frame 1ab (ORF1ab) and nucleocapsid protein (NP) gene fragments were amplified, and the conditions for amplification were $50^{\circ} \mathrm{C}$ for $10 \mathrm{~min}$ and $97^{\circ} \mathrm{C}$ for $1 \mathrm{~min}$, followed by 40 cycles of $97^{\circ} \mathrm{C}$ for $5 \mathrm{~s}$ and $58^{\circ} \mathrm{C}$ for $30 \mathrm{~s}$. When both targets (ORF1ab and NP) tested positive by specific real-time RT-PCR, the case was considered to be laboratory-confirmed. A cycle threshold value ( $\mathrm{Ct}$ value) less than 37 was defined as a positive test, and a $\mathrm{Ct}$ value more than 40 was defined as a negative test. A medium load, defined as a Ct value from 37 to 40, required confirmation by retesting.

\section{Serological COVID-19 RDT}

Serum was separated by centrifugation at $2500 \mathrm{~g}$ for 5 min within $24 \mathrm{~h}$ of collection.

The SARS-CoV-2 IgG/IgM RDT Kit from Innovita Biological Technology Co., Ltd. (Beijing, China) was used. Briefly, the assay was performed by adding $10 \mu \mathrm{l}$ of serum/plasma or $20 \mu \mathrm{l}$ of whole blood to 2 drops $(80 \mu \mathrm{l})$ of the assay buffer. Reacting bands were read after 15 min, and the density was determined as either negative or positive. The final results were agreed on by 3 investigators.

\section{Statistical analysis}

All statistical analyses were performed using SPSS version 16.0 (SPSS Inc). Means for continuous variables were compared using independent-group $t$ tests when the data were normally distributed; otherwise, the Mann-Whitney test was used. Binary logistic regression analysis was performed. Probability (p) values less than 0.05 were considered significant.

\section{Results \\ Epidemiological characteristics}

As of March 15, 2020, clinical data had been collected from 758 patients with laboratory-confirmed COVID-19 who were quarantined at rehabilitation stations in Huangpi, Wuhan, Hubei Province. Twenty-one (2.77\%) of the patients were $<10$ years old, $19(2.51 \%)$ were 10 19 years old, $76(10.02 \%)$ were $20-29$ years old, 148 (19.53\%) were $30-39$ years old, $153(20.18 \%)$ were 40 49 years old, 158 (20.84\%) were 50-59 years old, 120 (15.83\%) were 60-69 years old, $50(6.60 \%)$ were $70-79$ years old, and $13(1.72 \%)$ were 80 years old and older. The median age was 48 years (interquartile range $35-58$ years), and the mean (SD) age was $46.61(16.82)$ years (Table 1). A total of 396 patients $(51.40 \%)$ were male. All 758 patients had confirmed cases and had had 2 consecutive negative RT-PCR results separated by at least 1 day prior to hospital discharge.

Of these patients, $59(59 / 758,7.78 \%)$ had positive RT-PCR results when quarantined at rehabilitation stations. Of the 59 patients with recurrent positive RT-PCR results after hospital discharge, one (1.70\%) was < 10 years old, 1 (1.70\%) was $10-19$ years old, 9 (15.25\%) were $20-29$ years old, 10 (16.95\%) were 30 39 years old, 5 (8.47\%) were $40-49$ years old, 13 (22.03\%) were $50-59$ years old, 13 (22.03\%) were 60 69 years old, $4(15.83 \%)$ were $70-79$ years old, and 3 $(5.09 \%)$ were 80 years old and older. The median age was 52 years (interquartile range $35-65$ years), and the mean (SD) age was 49.61 (16.64) years. Twenty-nine patients $(49.15 \%)$ were male (Table 1$)$. 


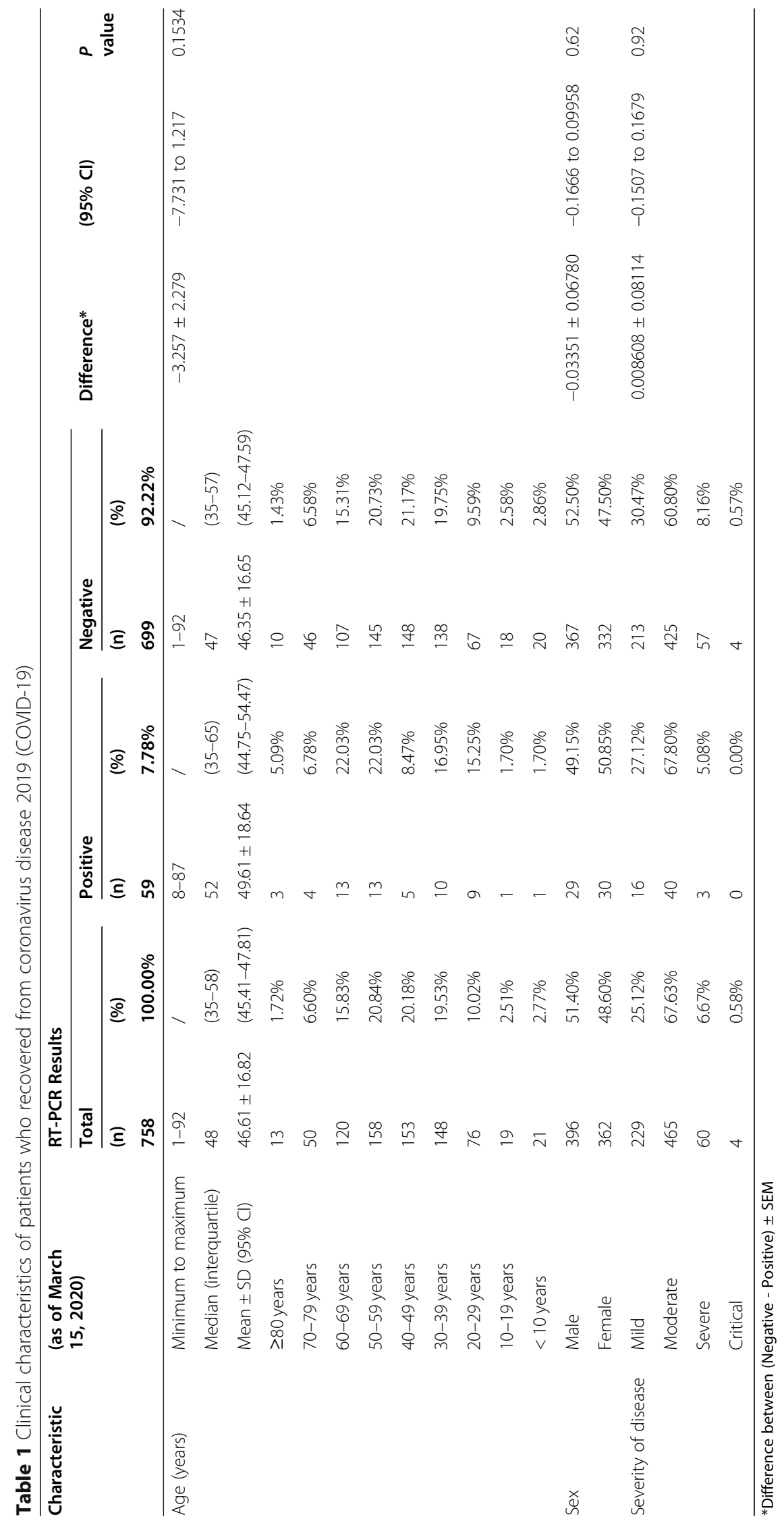




\section{Clinical features}

The severity of disease ranged from mild to critical among the 758 patients and from mild to severe among the 59 patients with recurrent positive RT-PCR results for SARS-CoV-2. Among the 758 patients, 229 (25.12\%) had mild cases, $465(67.63 \%)$ had moderate cases, 60 (6.67\%) had severe cases, and $4(0.58 \%)$ had critical cases; the severity was determined according to the guidelines for PC-NCP [1] (Table 1). Of the 59 patients who had recurrent positive RT-PCR results, 16 (27.12\%) had mild cases, $40(67.80 \%)$ had moderate cases, 3 $(5.08 \%)$ had severe cases, and $0(0.00 \%)$ had critical cases (Table 1).

Among all 758 patients, the time interval from the onset of symptoms to the first hospitalization ranged from 1 to 61 days. The median time from the onset of symptoms to the first hospital admission was 8 (3-13) days. The mean (SD) interval was 9.31 (7.78) days from the onset of symptoms to the first hospital admission. Among the 59 patients with recurrent positive RT-PCR results for SARS-CoV-2, the time interval from the onset of symptoms to the first hospitalization ranged from 1 to 33 days. The median time from the onset of symptoms to the first hospital admission was 6 (1-11) days. The mean (SD) interval from the onset of symptoms to the first hospital admission was 7.53 (7.15) days (Table 1). As of March 15, 2020, all patients were asymptomatic, and no more infections had been detected.

\section{Recurrent positive RT-PCR results for SARS-CoV-2}

Of the 59 patients with recurrent positive RT-PCR results for SARS-CoV-2 after hospital discharge, the time from the onset of symptoms to the last positive RT-PCR test result for SARS-CoV-2 ranged from 14 to 61 days. The median time from the onset of symptoms to the first hospital admission was 30 (23-39) days, and the mean (SD) interval was 31.78 (12.17) days. In addition, the time from diagnosis to the last positive RT-PCR test result for SARS-CoV-2 ranged from 13 to 48 days. The median and mean (SD) intervals from the onset of symptoms to the first hospital admission were 24 (2029) days and 25.53 (7.857) days, respectively. Last, the time from quarantine to the last positive RT-PCR test results ranged from 1 to 19 days. The median and mean (SD) intervals from the onset of symptoms to the first hospital admission were 8 (4-11) days and 7.746 (4.13) days, respectively (Table 2).

The timeline of recurrent positive RT-PCR findings in recovered COVID-19 patients in Wuhan, China, is shown in Fig. 1.

\section{Serological RDTs in patients with recurrent positive RT- PCR results for SARS-CoV-2}

The IgG and IgM antibodies for SARS-CoV-2 were detected in the 59 COVID-19 patients who had recurrent positive RT-PCR results for SARS-CoV-2 as of March 17, 2020. Fifty of $59(84.75 \%)$ patients had positive results for the IgG antibody against SARS-CoV-2, while 4 of 59 patients $(6.78 \%)$ had positive results for both IgM and IgG antibodies against SARS-CoV-2.

The details of the results of the serological RDTs in the patients with recurrent positive RT-PCR results for SARS-CoV-2 are listed in Table 3 and Fig. $1 \mathrm{~b}$.

Table 2 Characteristics of 59 patients who recovered from COVID-19 and had recurrent positive RT-PCR results

\begin{tabular}{|c|c|c|c|c|}
\hline & \multicolumn{4}{|c|}{ Positive RT-PCR Results } \\
\hline & \multicolumn{2}{|c|}{ From disease onset } & \multirow{2}{*}{$\begin{array}{l}\text { From diagnosis } \\
\text { Last time }\end{array}$} & \multirow{2}{*}{$\begin{array}{l}\text { From hospital discharge } \\
\text { Last time }\end{array}$} \\
\hline & First time & Last time & & \\
\hline Median (IQR) & $1(-2-7)$ & $30(23-39)$ & $24(20-29)$ & $8(4-11)$ \\
\hline Minimum to maximum & -35 & $14-61$ & $13-48$ & $1 / 19 / 2020$ \\
\hline Mean \pm SD & $4.153 \pm 7.701$ & $31.78 \pm 12.17$ & $25.53 \pm 7.857$ & $7.746 \pm 4.13$ \\
\hline $95 \% \mathrm{Cl}$ of the mean & $2.146-6.159$ & $28.61-34.95$ & $23.48-27.54$ & $6.67-8.822$ \\
\hline Last (weeks) $\geq 1$ week (n) & / & / & / & 23 \\
\hline$\geq 2$ weeks (n) & / & / & 1 & 33 \\
\hline$\geq 3$ weeks (n) & / & 11 & 15 & 3 \\
\hline$\geq 4$ weeks (n) & / & 15 & 25 & / \\
\hline$\geq 5$ weeks (n) & / & 9 & 12 & / \\
\hline$\geq 6$ weeks (n) & / & 15 & 5 & / \\
\hline$\geq 7$ weeks (n) & / & 3 & 3 & / \\
\hline$\geq 8$ weeks (n) & / & 2 & / & / \\
\hline$\geq 9$ weeks (n) & / & 4 & / & / \\
\hline
\end{tabular}




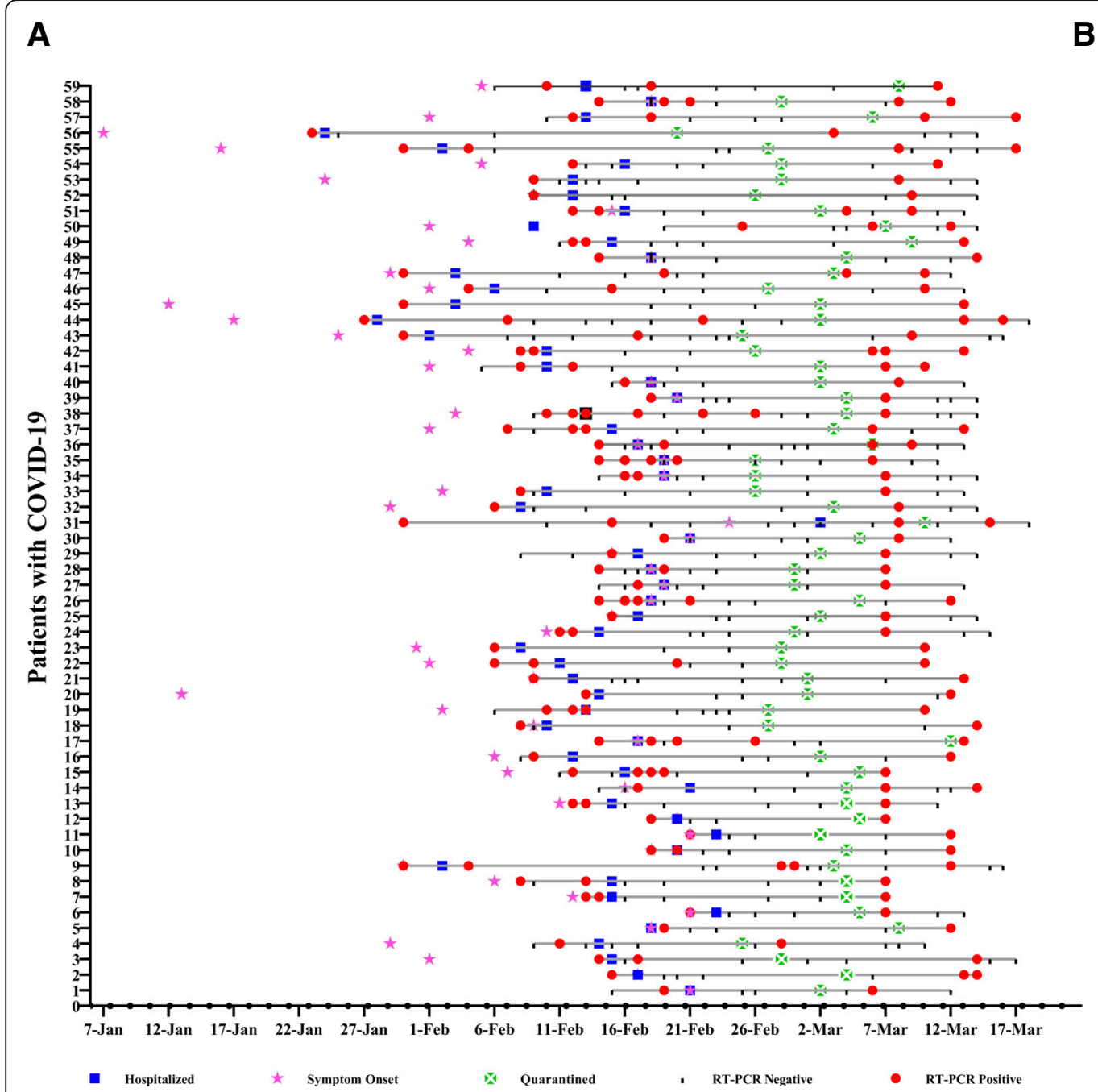

B

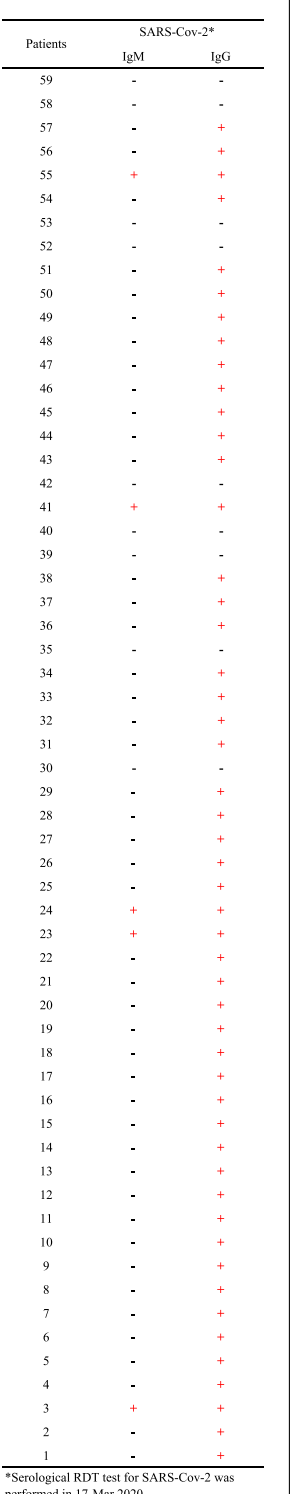

Fig. 1 The timeline of recurrent positive RT-PCR findings in patients who had recovered from COVID-19 in Wuhan, China. Details of the timeline (a) and serological RDT results (b) in recovered COVID-19 patients with recurrent positive RT-PCR findings in Wuhan, China

Table 3 The serological RDT results for patients with recurrent positive RT-PCR results for SARS-CoV-2

\begin{tabular}{llll}
\hline SARS-CoV-2 & RT-PCR $(\mathbf{n}, \%)$ & & Negative \\
\cline { 2 - 4 } & Total & Positive & $32(54.24 \%)$ \\
\hline Serological RDT & $59(100.00 \%)$ & $27(45.76 \%)$ & $2(6.25 \%)$ \\
lgM+ & $5(8.47 \%)$ & $3(11.11 \%)$ & $30(93.75 \%)$ \\
lgM- & $54(91.53 \%)$ & $24(88.89 \%)$ & $25(78.12 \%)$ \\
lgG+ & $50(84.75 \%)$ & $25(92.59 \%)$ & $7(21.88 \%)$ \\
lgG- & $9(15.25 \%)$ & $2(7.41 \%)$ & \\
\hline
\end{tabular}

No risk factor identified in the patients with recurrent RTPCR results for SARS-CoV-2

There were no significant differences in age, sex, disease severity, and time between disease onset and diagnosis between those with and without recurrent positive RTPCR results. Binary logistic regression analysis showed that age, sex, severity of disease, and time from onset to hospitalization were not risk factors for recurrent positive RT-PCR in quarantined recovered COVID-19 patients. Based on the current data, no risk factor was identified in the patients with recurrent positive RT-PCR results for SARS-CoV-2. 


\section{Discussion}

Few previous investigations have evaluated follow-up RT-PCR results for SARS-CoV-2 in patients who have recovered from COVID-19 [3-5]. A few reports have suggested that there are asymptomatic carriers of SARSCoV-2 who may be able to transmit the virus [6]. Our investigation suggests that among recovered COVID-19 patients, 7.78\% (59/758) have recurrent positive RT-PCR results for SARS-CoV-2, with most patients also having positive findings for IgG or IgG/IgM against SARS-CoV2 on the RDT. These results suggest that recurrent positive RT-PCR results for SARS-CoV-2 commonly appear in patients who have recovered from COVID-19.

Our results show a low prevalence $(7.78 \%$; $59 / 758)$ of recurrent positive RT-PCR results for SARS-CoV-2 in the throat swab specimens from recovered COVID-19 patients who were quarantined at the rehabilitation stations; these recurrent positive results occurred from 1 to 19 days after quarantine. The results were consistent with a previous study on positive RT-PCR results in patients who had recovered from COVID-19. Four patients with COVID-19 who met the criteria for hospital discharge or the discontinuation of quarantine in China (absence of clinical symptoms and radiological abnormalities and 2 negative RT-PCR results) had positive RT-PCR results 5 to 13 days later [3]. Two other studies also reported that PCR assays turned positive again in 25 of $172(14.5 \%)$ and 15 of 70 (21.4\%) discharged patients from Shenzhen [4] and Wuhan [5]. These findings confirmed that a certain proportion of recovered patients may still experience conversion and prolonged nucleic acid positivity regardless of the relief of symptoms and improvements on radiography.

First, RT-PCR has been widely employed in diagnosing viral infections and has yielded few false-positive results [7]. The observed false-negative results have been related to the quality of the kit, the collected sample, or the performance of the test [6]. In this study, specimens were obtained from patients from 17 hospitals who were quarantined at 32 rehabilitation stations, and RT-PCR was performed by trained professionals in a high-quality standardized laboratory. It is less likely that technical reasons were the cause of the recurrent positive RT-PCR results for SARS-CoV-2.

Second, several serological immunoassays have been developed by in vitro diagnostic (IVD) companies for the detection of SARS-CoV-2 viral proteins and antibodies in the serum or plasma. IgM can be detected in patient samples 10 to 30 days after SARS-CoV-2 infection, while IgG can be detected from 20 days onwards [8]. The IgM response occurs earlier than that of IgG, but it then decreases and disappears [9]. In this study, most patients with recurrent positive RT-PCR results
(50/59, 84.70\%) were positive for IgG against SARS$\mathrm{CoV}-2$, which implies that the patients had an immune response.

Third, it is presumed that asymptomatic carriers can transmit SARS-CoV-2 [6]. The possibility of transmission by patients who have recovered from COVID-19 and have recurrent positive RT-PCR results for SARS$\mathrm{CoV}-2$ needs further investigation.

Our study has several limitations. This study had a small sample size of patients with COVID-19. A larger cohort and more detailed follow-up would help elucidate the characteristics of recovered COVID-19 patients with recurrent positive RT-PCR results. In addition, because only basic information, including age, sex, severity of disease, and time from the onset of illness to diagnosis, was collected, no risk factors were found in this study. In the future, more patients need to be enrolled.

\section{Conclusions}

In this study, some recovered COVID-19 patients who had been quarantined had recurrent positive RT-PCR results for SARS-CoV-2. Although there was a low prevalence of recurrent positive RT-PCR results for SARSCoV-2 in recovered COVID-19 patients, most of them had evidence of an immune reaction, and the possibility of transmission of the virus by these patients needs further investigation.

\section{Abbreviations}

COVID-19: Coronavirus disease 2019; RT-PCR: Reverse transcriptasepolymerase chain reaction; IQR: Interquartile range; PC-NCP: Novel coronavirus pneumonia; RDT: Rapid diagnostic test

\section{Acknowledgements}

We thank Wen-sheng Lei from the Huangpi District Center for Disease Control and Prevention for collecting data from recovered COVID-19 patients and Chao Ma from the Chinese Center for Disease Control and Prevention for advice regarding the manuscript. We thank the CDC employees, clinicians, and medical laboratory specialists studying COVID-19 in Huangpi, Wuhan, for their excellent assistance with data collection. We also thank the patients for their participation in this study.

\section{Authors' contributions}

Conceived of and designed the experiments: TS and BZ. Collected data: TS, $\mathrm{CL}$, and $\mathrm{HL}$. Analysed the data and wrote the paper: XC. All authors have read and approved the manuscript.

\section{Authors' information}

Tie-jun Shui is a deputy director and physician in the Yunnan Center for Disease Control and Prevention, Yunnan, China. She mainly works on the epidemiology of infectious diseases.

Chao Li is a physician in the Huangpi District Center for Disease Control and Prevention, Wuhan, China. She mainly works on statistical analyses and processing.

Funding

This study was not funded.

Availability of data and materials

The datasets used and/or analysed during the current study are available from the corresponding author on reasonable request. 


\section{Ethics approval and consent to participate}

This study was approved by the Medical Ethics Committee of the Yunnan Center for Disease Control and Prevention, Yunnan, People's Republic of China. Written informed consent was obtained from all adult participants and all parents/guardians of the study participants who were under the age of 16 years. Patients were informed that their participation was voluntary. Study participants were also informed about the purpose of the study. Confidentiality was maintained at all levels of the study. In addition, study participant involvement was on a voluntary basis, and participants who were unwilling to take part in the study and those who needed to quit their participation at any stage were told they could do so without any restrictions.

\section{Consent for publication}

Not Applicable.

\section{Competing interests}

The authors declare that they have no competing interests.

\section{Author details}

${ }^{1}$ Yunnan Center for Disease Control and Prevention, Kunming 650011, Yunnan, China. ${ }^{2}$ Huangpi District Center for Disease Control and Prevention, Wuhan 432200, China. ${ }^{3}$ Lincang City Center for Disease Control and Prevention, Lincang 677000, Yunnan, China. ${ }^{4}$ Beijing Tropical Medicine Research Institute, Beijing Friendship Hospital, Capital Medical University, Beijing 100050, China. ${ }^{5}$ Beijing Key Laboratory for Research on Prevention and Treatment of Tropical Diseases, Capital Medical University, Beijing 100050, China. ${ }^{6}$ Chinese Center for Disease Control and Prevention, Beijing 102206, China.

Received: 16 April 2020 Accepted: 30 September 2020

Published online: 13 October 2020

\section{References}

1. China National Health Commission. Diagnosis and treatment of 2019-nCoV Pneumonia in China. In Chinese. Published February 8, 2020. http://www. nhc.gov.cn/yzygj/s7653p/202002/d4b895337e19445f8d728fcaf1e3e13a.shtml. Accessed 19 Feb 2020

2. Liu R, Han H, Liu F, Lv Z, Wu K, Liu Y, et al. Positive rate of RT-PCR detection of SARS-CoV-2 infection in 4880 cases from one hospital in Wuhan, China, from Jan to Feb 2020. Clin Chim Acta. 2020;505:172-5.

3. Lan L, Xu D, Ye G, Xia C, Wang S, Li Y, et al. Positive RT-PCR test results in patients recovered from COVID-19. JAMA. 2020;323:1502-3.

4. Xiao AT, Tong YX, Zhang S. False-negative of RT-PCR and prolonged nucleic acid conversion in COVID-19: rather than recurrence. J Med Virol. 2020. https://doi.org/10.1002/jmv.25855.

5. Yuan J, Kou S, Liang Y, Zeng J, Pan Y, Liu L. PCR assays turned positive in 25 discharged COVID-19 patients. Clin Infect Dis. 2020:ciaa398. https://doi.org/ 10.1093/cid/ciaa398.

6. Wang D, Hu B, Hu C, Zhu F, Liu X, Zhang J, et al. Clinical characteristics of 138 hospitalized patients with 2019 novel coronavirus-infected pneumonia in Wuhan, China. JAMA. 2020;323:1061-9.

7. Corman VM, Landt O, Kaiser M, Molenkamp R, Meijer A, Chu DK, et al. Detection of 2019 novel coronavirus (2019-nCoV) by real-time RT-PCR. Euro Surveill. 2020;25:2000045.

8. Tan W, Lu Y, Zhang J, Wang J, Dan Y, Tan Z, et al. Viral kinetics and antibody responses in patients with COVID-19. medRxiv. 2020. https://www. medrxiv.org/content/10.1 101/2020.03.24.20042382v1.full.pdf.

9. Vashist SK. In vitro diagnostic assays for COVID-19: recent advances and emerging trends. Diagnostics (Basel). 2020;10:E202.

\section{Publisher's Note}

Springer Nature remains neutral with regard to jurisdictional claims in published maps and institutional affiliations. 